\title{
MATHEMATICAL MODELING OF HEAT TRANSFER IN THE SYSTEM "THE OBJECT OF HEATING - THERMAL INSULATION LAYER - THE EXTERNAL ENVIRONMENT" AND MICROCLIMATE PARAMETERS INDUSTRIAL PREMISES
}

\author{
M. A. Ulchiekov ${ }^{1, *}$ \\ ${ }^{1}$ National research Tomsk Polytechnic University, Tomsk 634050, Russia
}

\begin{abstract}
This paper been solved the task of thermal conductivity for the system "the object of heating - thermal insulation layer - the external environment." The impact of the main groups of factors on the temperature of heating the object surface has been shown.
\end{abstract}

\section{Introduction}

Development of heat supply facilities industrial objects is carried out using standard parameters $[1,2]$. The choice of heating system parameters, usually is intended to achieve the temperature in the room $T_{A}$, which provide thermal comfort [3] conditions of work regulations of the microclimate. Selection $T_{\mathrm{A}}$ same indoor air temperature is carried out mainly "heuristic" (based on operating experience of heating systems). Thus, as a rule, merely postulated that is comfortable for the operating temperature range of variation from $18{ }^{\circ} \mathrm{C}$ to $24{ }^{\circ} \mathrm{C}$. This approach provides acceptable for traditional heating systems technology of work, without taking into account the possible individual characteristics of the main object of heat - working and production conditions (intensity, the presence of breaks, clothing type, mode of operation of the ventilation system, and others.) In this context, it seems appropriate to analyze the processes of heat removal (cooling) from the working and theoretical foundation of the currently accepted on the basis of empirical data on how working senses temperature industrial premises.

The purpose of the study is the solution of heat conduction problem for a system of "the object of heating - thermal insulation layer - the external environment" and the establishment of the numerical values of the heat flows from the surface of the body working, which correspond to the currently accepted conditions of the "thermal comfort".

Corresponding author: ulchieckovmihail@mail.ru 


\section{Formulation of the problem}

At the problem formulation it was assumed that the temperature of the main body of the human $T_{1}$ is constant and may vary within certain limits, from $35.5^{\circ} \mathrm{C}$ to $36.8^{\circ} \mathrm{C}$. Out of this range is possible, but this is the exception rather than the rule. More intense heat dissipation into the environment may lead to a decrease in $T_{l}$, but in real conditions such a deviation can not be more than $0.8^{\circ} \mathrm{C}$, even in the lowest permissible ambient temperature.

System, which is regarded (fig. 1), consists of seven heating elements: the main part of the human body with a constant temperature for a long time; adjacent to the surface layer of the skin, consisting of three elements (subcutaneous fat, dermis and epidermis), which in real conditions there is a temperature difference, the air gap of small thickness between the human skin and clothing; clothes, performing the function of heat insulation; the external environment, the temperature of which may be taken as a first approximation constant.

In this formulation, the problem is reduced to the determination of the working body surface temperature $T_{S}$ in certain thicknesses of the layers (fig. 1), thermal insulation properties of materials and substances, as well as the heat sink conditions on the outer boundary layer of insulation. The $T_{S}$ temperature will determine the "comfort" heat mode working at a certain ambient temperature and cooling rate. Formulated heat conduction problem can be solved in one-dimensional formulation (cross-flow heat on the other two coordinates are negligible in most practically important variants) for the five-layer plate.

It should be noted that in general it is possible to vary parameters of the system - as the thicknesses of the individual layers and the heat insulating characteristics of the materials of these layers. Therefore, one characteristic of the process which determines at the simulation can be a surface body temperature of working $T_{S}$ assuming the temperature $T_{l}$ at a certain distance from the surface is constant (which is justified as a rule).

Solutions field geometry is shown in fig. 1 .

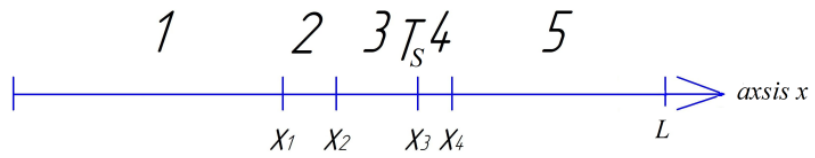

Fig.1. Field of solving the problem: 1) the subcutaneous fat; 2) the dermis; 3) the epidermis; 4) the air layer; 5) the thermal insulation (clothing).

Mathematical modeling of the process under study is reduced to solving a system of five equations of heat conduction for the system "the object of heating - air gap - a layer of thermal insulation - the external environment" with the appropriate boundary conditions.

In this case, we consider a linear one-dimensional heat conduction problem.

The mathematical formulation of the problem:

$$
\left\{\begin{array}{l}
\rho_{1} c_{1} \frac{\partial T_{1}}{\partial t}=\lambda_{1} \frac{\partial^{2} T_{1}}{\partial x^{2}}, 0<x<x_{1} \\
\rho_{2} c_{2} \frac{\partial T_{2}}{\partial t}=\lambda_{2} \frac{\partial^{2} T_{2}}{\partial x^{2}}, x_{1}<x<x_{2} \\
\rho_{3} c_{3} \frac{\partial T_{3}}{\partial t}=\lambda_{3} \frac{\partial^{2} T_{3}}{\partial x^{2}}, x_{2}<x<x_{3} \\
\rho_{4} c_{4} \frac{\partial T_{4}}{\partial t}=\lambda_{4} \frac{\partial^{2} T_{4}}{\partial x^{2}}, x_{3}<x<x_{4} \\
\rho_{5} c_{5} \frac{\partial T_{5}}{\partial t}=\lambda_{5} \frac{\partial^{2} T_{5}}{\partial x^{2}}, x_{4}<x<L
\end{array}\right.
$$


Here $\rho_{i}, \lambda_{i}, c_{i}$ - density, coefficient of thermal conductivity and specific heat of the material of $i$-layer system, $T_{i}-$ current temperature value $(i=1$ to 5$)$.

On the outside $(x=L)$ surface of the insulation layer the heat exchange takes place with the environment, which is described by the boundary conditions of the third kind, and thermal interaction between the layers of the system is described by the the fourth kind boundary conditions.

The initial and boundary conditions:

$$
\begin{aligned}
& x=0: T=T_{1}, T_{1}=\text { const } \\
& x=x_{1}: \lambda_{1} \frac{\partial T_{1}}{\partial x}=\lambda_{2} \frac{\partial T_{2}}{\partial x}, T_{1}=T_{2} ; \\
& x=x_{2}: \quad \lambda_{2} \frac{\partial T_{2}}{\partial x}=\lambda_{3} \frac{\partial T_{3}}{\partial x}, T_{2}=T_{3} ; \\
& x=x_{3}: \quad \lambda_{3} \frac{\partial T_{3}}{\partial x}=\lambda_{4} \frac{\partial T_{4}}{\partial x}, T_{3}=T_{4} ; \\
& x=x_{4}: \quad \lambda_{4} \frac{\partial T_{4}}{\partial x}=\lambda_{5} \frac{\partial T_{5}}{\partial x}, T_{4}=T_{5} ; \\
& x=L: \quad \lambda_{5} \frac{\partial T_{5}}{\partial x}=\alpha\left(T_{L}-T_{A}\right) ; \\
& t=0: \quad T_{1}=T_{1}^{0}, T_{2}=T_{2}^{0}, \ldots . ., T_{x 1}=T_{x 1}^{0}, 0<x<x_{3} ; \\
& \quad T=T_{0}^{a}, x_{3}<x<x_{4} ; \\
& \quad T=T_{0}^{c l}, x_{4}<x<L ;
\end{aligned}
$$

Here $T_{A}$ - ambient temperature, $\alpha$ - heat transfer coefficient.

The system of differential equations with appropriate initial and boundary conditions solved by finite difference method, using an algorithm [4,5] developed for solving problems of heat transfer in the fields of multi-layer with discontinuities coefficients of thermal conductivity.

\section{Numerical investigations}

Investigations were carried out for different temperature of the environment $\mathrm{T}_{\mathrm{A}}$ (from 291 $K$ to $297 \mathrm{~K})$, thicknesses of the air layer $\Delta 4(0.0005 \mathrm{~m}$ to $0.002 \mathrm{~m})$, thicknesses of the clothes $\Delta 5$ (from $0.002 \mathrm{~m}$ to $0.007 \mathrm{~m}$ ).

Thermophysical characteristics of the layers the system under consideration [6,7]:

$\lambda_{1}=0.2 \mathrm{~W} / \mathrm{m} \cdot K, \lambda_{2}=0.45 \mathrm{~W} / \mathrm{m} \cdot K, \lambda_{3}=0.21 \mathrm{~W} / \mathrm{m} \cdot K, \lambda_{4}=0.024 \mathrm{~W} / \mathrm{m} \cdot \mathrm{K}$,

$\lambda_{5}=0.03 \mathrm{~W} / \mathrm{m} \cdot K$

$\rho_{1}=850 \mathrm{~kg} / \mathrm{m}^{3}, \rho_{2}=1000 \mathrm{~kg} / \mathrm{m}^{3}, \rho_{3}=1200 \mathrm{~kg} / \mathrm{m}^{3}, \rho_{4}=1.2 \mathrm{~kg} / \mathrm{m}^{3}, \rho_{5}=120 \mathrm{~kg} / \mathrm{m}^{3}$

$c_{1}=2250 \mathrm{~J} / \mathrm{kg} \cdot \mathrm{K}, c_{2}=3200 \mathrm{~J} / \mathrm{kg} \cdot \mathrm{K}, c_{3}=3600 \mathrm{~J} / \mathrm{kg} \cdot \mathrm{K}$,

$c_{4}=1005 \mathrm{~J} / \mathrm{kg} \cdot \mathrm{K}, c_{5}=2260 \mathrm{~J} / \mathrm{kg} \cdot \mathrm{K}$,

The geometrical characteristics of the layers skin [8]:

$$
\Delta_{1}=0.015 \mathrm{~m}, \Delta_{2}=0.0005 \mathrm{~m}, \Delta_{3}=0.001 \mathrm{~m}
$$

Conditions of the heat exchange with the environment:

$$
T_{0}^{c l}=301 \mathrm{~K}, T_{0}^{a}=303 \mathrm{~K}, T_{0}^{x 1}=307, \alpha=5 \mathrm{~W} / \mathrm{m}^{2} \cdot \mathrm{K} .
$$

The duration of the modeled process: $t=7000 \mathrm{~s}$.

Fig. 2 shows the temperature field in the investigated systems at various ambient temperatures. 


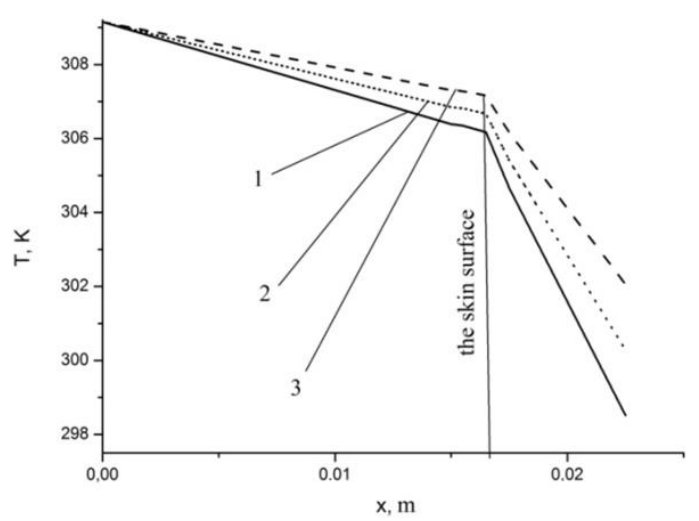

Fig. 2. The temperature distribution along the $x$ coordinate at: $1-T_{A}=291 K ; 2-T_{A}=294 K ; 3-$ $T_{A}=297 \mathrm{~K}$.

Fig. 3 shows the temperature of the skin surface dependence from the time at various ambient temperatures. It has been established that certain $T_{S}$ falls to values corresponding to the conditions of heat transfer at the boundary $x=L$, and further does not change.

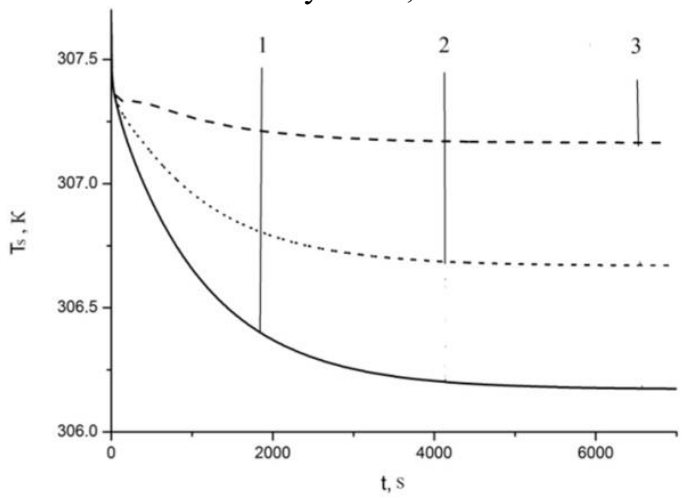

Fig. 3. $T_{S}$ dependence on time at: $1-T_{A}=291 K ; 2-T_{A}=294 \mathrm{~K} ; 3-T_{A}=297 \mathrm{~K}$.

Fig. 4 shows the dependence temperature of heating surface of the object on the value of the $\mathrm{T}_{\mathrm{A}}$. This dependence is linear and the change of the $\mathrm{T}_{\mathrm{S}}$ is $0.9 \mathrm{~K}$ at the ambient temperature change of $6 \mathrm{~K}$.

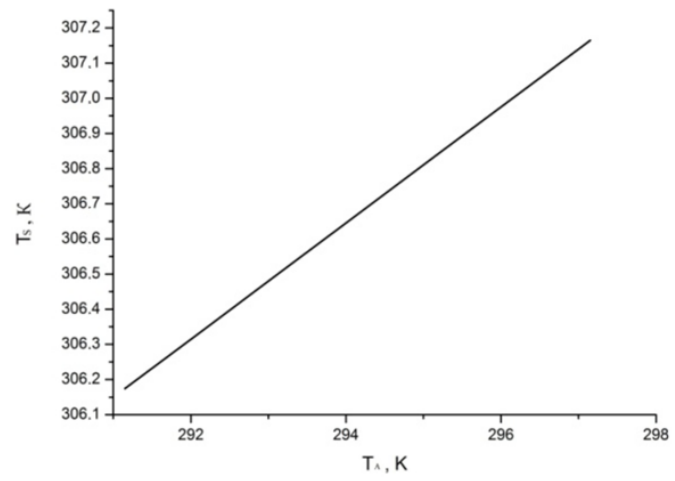

Fig. 4. The dependence of the $T_{S}$ on the ambient temperature.

Fig. 5 shows the dependence $T_{S}$ of the thickness air gap at different ambient temperatures. The change is from $0.24 \mathrm{~K}$ to $0.3 \mathrm{~K}$ with change $\Delta 4$ to $0.0015 \mathrm{~m}$. 


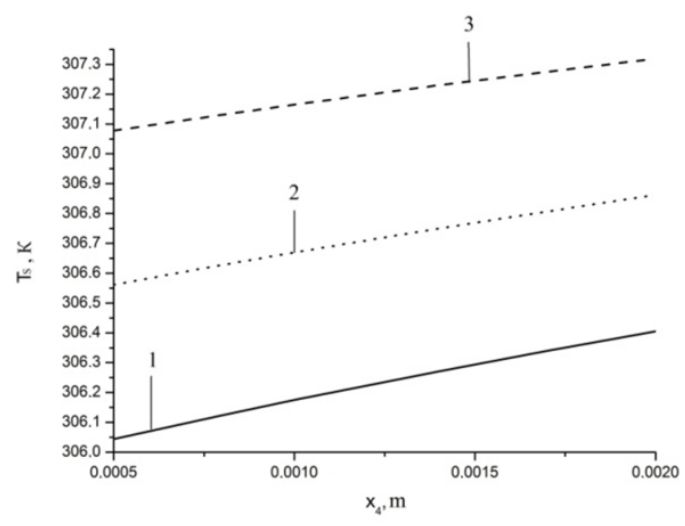

Fig. 5. The dependence of the $T_{\mathrm{S}}$ on the thicknesses of the air layer : $1-T_{A}=291 K ; 2-T_{A}=294$ $K ; 3-T_{A}=297 K$.

Fig. 6 shows the dependence $T_{S}$ of the thickness of the outer thermal insulation at various ambient temperatures. The change is from $0.748 \mathrm{~K}$ to $1.124 \mathrm{~K}$ at changing $\Delta 5$ to $0.005 \mathrm{~m}$.

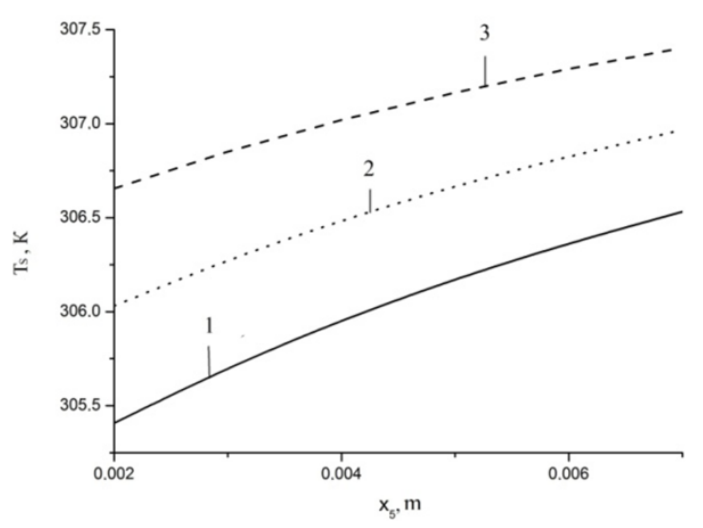

Fig. 6. The dependence of the $T_{S}$ on the thicknesses of the thermal insulation: $1-T_{A}=291 K ; 2-$ $T_{A}=294 \mathrm{~K} ; 3-T_{A}=297 \mathrm{~K}$.

\section{Conclusions}

1. The mathematical model heat transfer in the system "heating facility - thermal insulation layer - the external environment", by heat exchange with the environment in a natural convection mode is formulated, which differs from the known a high-level of field sampling solutions in the description of the heat transfer processes in the considered system and a possible forecast of microclimate parameters .

2. The influence the main groups of factors on the surface temperature of the heating object. 


\section{Acknowledgments}

The work was supported by the Russian Federation President's grant (NSH project 7538.2016.8).

\section{References}

1. P. Domingues, P. Carreira, R. Vieira, W. Kastner, Comp. St. Int. 45 (2016)

2. M Wallance, R. McBride., P. Mhaskar, , J. House, T. Salsbury, Ch. Eng. Sc. Energy 69 (2012)

3. M. Taleghani, M. Tenpierik, A. Dobbelsteen, Ren. Sust. En. R. 26 (2013)

4. O.V. Vysokomornaya, G.V. Kuznetsov, P.A. Strizhak, Rus. J. Ph. Ch. B 5 (2011)

5. V.L. Strakhov, A.N. Garashchenko, G.V. Kuznetsov, V.P. Rudzinskii, Comb., Exp. Sh. W. 37 (2001)

6. I.K. Kikoin Tables of physical quantities (Atomizdat, Moscow, 1976)

7. A.P. Babichev, A.P. Babushkin, A.M. Bratkovsky Physical values, (Eneroatomizdat, Moscow, 1991)

8. F. Xu, T. J Lu, K. A., Sef. Acta Mech. S. 24 (2008) 